\title{
Drug utilization pattern and rational drug use at orthopedics and traumatology outpatient clinics: A cross-sectional study
}

\author{
İhsan Özdamar, MD'1D, Emine Nur Özdamar, $\mathrm{MD}^{2} \mathbb{B}$ \\ 1'Department of Orthopedics and Traumatology, Sancaktepe Şehit Prof. Ilhan Varank Training and Research Hospital, Istanbul, Turkey \\ ${ }^{2}$ Department of Medical Pharmacology, Yeditepe University Faculty of Medicine, Istanbul, Turkey
}

In parallel with the developments in medicine in the last century, the increasing number and use of drugs with the intent of the diagnosis and remediation of diseases necessitate the physicians to act rationally during the use of drugs. Rational drug use is described by the World Health Organization (WHO) as the body of rules that necessitate patients to use the drugs in conformity with their clinical necessities, at doses sufficient to fulfill their personal needs, within adequate time and least expenditure to them and the society. ${ }^{[1]}$ The steps of rational drug use are making the correct diagnosis of the patient, defining the problem carefully, establishing the treatment goals, selecting the most effective and safe therapy among the treatment options, appropriate prescribing, and monitoring and evaluation of the treatment results. ${ }^{[2]}$

Received: April 29, 2021

Accepted: August 12, 2021

Published online: November 19, 2021

Correspondence: İhsan Özdamar, MD. Sancaktepe Şehit Profesör Dr. İlhan Varank Eğitim ve Araştırma Hastanesi,

Ortopedi ve Travmatoloji Kliniği,

34785 Sancaktepe, İstanbul, Türkiye.

E-mail: ozdmrihsan@gmail.com

Doi: 10.52312/jdrs.2021.211

Citation: Özdamar İ, Özdamar EN. Drug utilization pattern and rational drug use at orthopedics and traumatology outpatient clinics: A cross-sectional study. Jt Dis Relat Surg 2021;32(3):759-766.

(2021 All right reserved by the Turkish Joint Diseases Foundation

This is an open access article under the terms of the Creative Commons Attribution-NonCommercial License, which permits use, distribution and reproduction in any medium, provided the original work is properly cited and is not used for commercial purposes (http://creativecommons.org/licenses/by-nc/4.0/).

\section{ABSTRACT}

Objectives: The aim of the present study was to assess the prescriptions of patients who were admitted to the orthopedics and traumatology outpatient clinic of a tertiary care hospital according to the WHO prescribing indicators.

Patients and methods: Between January 2020 and March 2020, a total of 1,024 patients (273 males, 751 females; mean age: $51.9 \pm 13.9$ years; range, 19 to 103 years) were included in the study. Only patients who were prescribed drugs and 18 years of age or older were included in the study. The WHO core prescribing indicators were utilized for the assessment of rational drug use. The WHO prescribing indicators percentages between the age categories were analyzed. The average number of drugs between the age categories was also examined.

Results: The average number of drugs per encounter was 2.9. The percentage of encounters with an antibiotic prescribed was $2.6 \%$ and with an injection prescribed was $10.7 \%$. The percentage of drugs prescribed from essential drugs list was $33.8 \%$. There were no prescriptions consisting generic name of drugs $(0 \%)$. Polypharmacy was significantly higher in the $\geq 65$ age group compared to the 18-44 age group $(\mathrm{p}=0.001)$.

Conclusion: The percentage of encounters with an antibiotic and injection prescribed were optimal according to WHO standards, while the average number of drugs per encounter was higher than the WHO ideal ranges. Unfortunately, the parameters such as the percentage of prescribing with generic name and from essential drug list was far more behind the optimal range.

Keywords: Drug utilization; polypharmacy; orthopedics; World Health Organization.

Irrational drug use refers to the use of drugs that are not appropriate for rational use according to the definition above. Redundant use of drugs per patient (polypharmacy), improper use of antibiotics, preferring injections when oral intake would be more appropriate, administering drugs that do not comply with clinical guidelines, and non-compliance 
with drug therapy by patients are widespread instances of irrational drug use. ${ }^{[3]}$ According to the WHO, more than half of the medications are prescribed incompliantly. ${ }^{[1]}$ Irrational drug use is still an important health problem all over the world, particularly in the least developed countries. As a consequence of unnecessary and improper drug administration, many health problems that may even result in death may occur. ${ }^{[4]}$ In particular, drug-drug interactions, development of resistance to medications, enhancement in the incidence of adverse drug reactions, and decrease in treatment compliance are the main problems that may arise due to irrational drug use. ${ }^{[4-6]}$

The WHO improved core drug use indicators (prescribing indicators, patient care indicators and health facility indicators) which provides a good quantitative assessment of rational drug use. ${ }^{[7,8]}$ The WHO prescribing indicators ensure beneficial data in evaluating the rational drug use particularly in the least developed countries. ${ }^{[9]}$

The clinical trials in orthopedics and traumatology have been mainly focused on surgical procedures. In this respect, it is important to evaluate the rational drug use in orthopedics and traumatology clinics. In the present study, we, therefore, aimed to assess the prescriptions of patients who applied to the orthopedics and traumatology outpatient clinic of a tertiary care hospital according to the WHO prescribing indicators.

\section{PATIENTS AND METHODS}

This cross-sectional, retrospective study was conducted at the orthopedics and traumatology outpatient clinic of Sancaktepe Şehit Profesör Ilhan Varank Training and Research Hospital between January $1^{\text {st }}, 2020$ and March $1^{\text {st }}, 2020$. Of a total of 3,689 patients who were admitted to our clinic 2,665 who were not prescribed any drugs or aged below 18 years of age were excluded. Finally, a total of 1,024 patients (273 males, 751 females; mean age: $51.9 \pm 13.9$ years; range, 19 to 103 years) were included in the study. Only patients who were prescribed drugs and 18 years of age or older were included in the study. The orthopedics and traumatology outpatient clinic prescriptions which covered at least one or more drugs were analyzed. The variables assessed included demographic characteristics of the patients (age, sex), International Classification of Disease (ICD-10) codes, clinical diagnoses, number of drugs prescribed, the Anatomical Therapeutical Chemical (ATC) codes and name of drugs, pharmaceutical dosage forms, routes of drug delivery, presence of antibiotics and injections in the prescription, whether drugs were prescribed by generic name or not, and whether drugs were prescribed from essential drugs list or not. Assessment of the repetitive prescriptions of the same patients and data duplications were hampered by recording the first prescription of the patient in the database. The WHO core prescribing indicators were utilized for the assessment of

\section{TABLE I}

The calculation and optimal levels of prescribing indicators according to WHO's manual[7]

\begin{tabular}{|lll}
\hline The WHO core prescribing indicators & Calculation & WHO optimal levels \\
\hline Average number of drugs per encounter & $\begin{array}{l}\text { Divide the total number of drugs prescribed by the } \\
\text { number of participants surveyed }\end{array}$ \\
Percentage of drugs prescribed by generic name & $\begin{array}{l}\text { Divide the number of drugs prescribed by generic } \\
\text { name by total number of drugs prescribed and } \\
\text { multiply by } 100\end{array}$ \\
Percentage of encounters with an antibiotic & $\begin{array}{l}\text { Divide the number of participants who were } \\
\text { prescribed an antibiotic by the total number of } \\
\text { prescribed }\end{array}$ & $\begin{array}{l}\text { participants surveyed and multiply by } 100 \\
\text { Divide the number of participants who were }\end{array}$ \\
Percentage of encounters with an injection & prescribed an injection by the total number of \\
prescribed & participants surveyed and multiply 100 \\
Percentage of drugs prescribed from essential & Divide the number of drugs prescribed which were \\
drugs list & $\begin{array}{l}\text { listed in essential drugs list by the total number of } \\
\text { drugs prescribed and multiply by } 100 .\end{array}$ \\
\hline WHO: World Health Organization. &
\end{tabular}


rational drug use. The calculation and optimal levels of prescribing indicators according to $\mathrm{WHO}$ manual are depicted in Table I. ${ }^{[7]}$

A written informed consent was obtained from each patient. The study protocol was approved by the Marmara University Faculty of Medicine Ethics Committee (IRB No: 09.2020.843, Date: 24/07/2020). The study was conducted in accordance with the principles of the Declaration of Helsinki.

\section{Statistical analysis}

The sample size calculation was based on a previous study of Yazıcıŏglu and Erdoğan. ${ }^{[10]}$ The study power was calculated as $98.3 \%$.

Statistical analysis was performed using the IBM SPSS version 25.0 software (IBM Corp., Armonk, NY, USA). Descriptive data were expressed in mean \pm standard deviation (SD), median (min-max) or number and frequency, where applicable. The chi-square test was used to compare the percentages of the WHO prescribing indicators between age categories. The Kruskal-Wallis test and post-hoc pairwise comparisons were used to compare the average number of drugs between age categories. A $p$ value of $<0.05$ was considered statistically significant.

\section{RESULTS}

Almost half of the patients (47.7\%) were in the 45-64 years age category (Table II). According to the clinical diagnosis, 'pain in joint' (ICD-10 code: M25.5; 42.3\%) was the most frequent diagnosis. Top 10 clinical diagnoses detected at orthopedics and traumatology outpatient clinic are depicted in Figure 1.

\begin{tabular}{|c|c|c|c|}
\hline \multicolumn{4}{|c|}{ TABLE II } \\
\hline Variables & $n$ & $\%$ & Mean $\pm S D$ \\
\hline Age (year) & & & $51.9 \pm 13.9$ \\
\hline \multicolumn{4}{|c|}{ Drug prescription } \\
\hline Yes & 1,024 & 27.8 & \\
\hline No & 2,665 & 72.2 & \\
\hline Total & 3,689 & 100.0 & \\
\hline \multicolumn{4}{|l|}{ Sex } \\
\hline Female & 751 & 73.3 & \\
\hline Male & 273 & 26.7 & \\
\hline Total & 1,024 & 100.0 & \\
\hline \multicolumn{4}{|c|}{ Age Groups } \\
\hline $18-44$ & 334 & 32.6 & \\
\hline $45-64$ & 488 & 47.7 & \\
\hline$\geq 65$ & 202 & 19.7 & \\
\hline Total & 1,024 & 100.0 & \\
\hline
\end{tabular}

A total of 3,004 drugs were prescribed to 1,024 patients. Most of the patients $(79.8 \%)$ were prescribed two to four drugs, while the prescriptions containing $>5$ drugs constituted a small percent $(7.5 \%)$ (Table III). According to the route of drug delivery, oral (92.0\%) and topical (79.3\%) route of administrations were the most common ways. According to the pharmaceutical dosage forms, tablets $(80.0 \%)$ and gels (76.4\%) were the most frequent ones (Table III).

Of a total of 3,004 drugs were prescribed, "Musculoskeletal system drugs" (ATC-1 code: M; 69.3\%) were the most commonly prescribed ATC-1 group. According to the ATC-2 group evaluation, "Anti-inflammatory and antirheumatic products" (ATC-1 code: M01; 38.5\%) were the most frequently prescribed group. According to the drug names, pantoprazole (ATC-5 code: A02BC02; 11.4\%), diclofenac (M01AB05; 7.1\%) and dexketoprofen+thiocolchicoside (M02AA27+M03BX05; 7.0\%) were the most commonly prescribed drugs, respectively. ATC-1 groups, top

\section{TABLE III}

Drug use characteristics of the patients $(n=1,024)$

\begin{tabular}{|c|c|c|}
\hline Variables & $\mathrm{n}$ & $\%$ \\
\hline \multicolumn{3}{|l|}{ Number of drugs } \\
\hline 1 & 130 & 12.7 \\
\hline $2-4$ & 817 & 79.8 \\
\hline$\geq 5$ & 77 & 7.5 \\
\hline \multicolumn{3}{|l|}{ Routes of drug delivery } \\
\hline Oral & 942 & 92.0 \\
\hline Topical & 812 & 79.3 \\
\hline Intraarticular & 70 & 6.8 \\
\hline Intramuscular & 24 & 2.3 \\
\hline Subcutaneous & 14 & 1.4 \\
\hline Intravenous & 1 & 0.1 \\
\hline \multicolumn{3}{|c|}{ Pharmaceutical dosage forms } \\
\hline Tablet & 819 & 80.0 \\
\hline Topical gel & 782 & 76.4 \\
\hline Capsule & 308 & 30.1 \\
\hline Sugar-coated pill & 135 & 13.2 \\
\hline Effervescent tablet & 109 & 10.6 \\
\hline Ampoule & 95 & 9.3 \\
\hline Vial & 35 & 3.4 \\
\hline Topical cream & 25 & 2.4 \\
\hline Oral drop & 16 & 1.6 \\
\hline Pre-filled syringe & 14 & 1.4 \\
\hline Sachet & 9 & 0.9 \\
\hline Topical spray & 8 & 0.8 \\
\hline Pomade & 4 & 0.4 \\
\hline Liquid & 2 & 0.2 \\
\hline
\end{tabular}


10 ATC-2 groups, and top 10 drugs prescribed are shown in Table IV.

According to the prescriptions based on the WHO core prescribing indicators, the average number of drugs per encounter was 2.9. The percentage of encounters with an antibiotic prescribed was 2.6\% and with an injection prescribed was $10.7 \%$. The percentage of drugs prescribed from essential drugs list was $33.8 \%$. There was no prescription consisting generic name of drugs $(0 \%)$ (Table V).
Polypharmacy was significantly higher in the $\geq 65$ age group than the $18-44$ age group $(p=0.001)$. The percentage of drugs prescribed from essential drugs list was significantly lower in the 18-44 age group (28.4\%), compared to the other age categories $(\mathrm{p}=0.038)$. On the other hand, there were no significant association of prescribing antibiotics $(\mathrm{p}=0.776)$ and injections ( $p=0.123$ ) with the age groups. Comparison of the WHO core prescribing indicators according to the age categories is depicted in Table VI.

\begin{tabular}{|c|c|c|}
\hline \multicolumn{3}{|c|}{$\begin{array}{l}\text { TABLE IV } \\
\begin{array}{l}\text { ATC-1 distributions and top } 10 \text { ATC-2 distributions of drugs and top } 10 \text { drugs prescribed at the } \\
\text { orthopedics and traumatology outpatient clinic }(n=3,004)\end{array}\end{array}$} \\
\hline Variables & $\mathrm{n}$ & $\%$ \\
\hline \multicolumn{3}{|l|}{ ATC-1 codes } \\
\hline Musculoskeletal system (M) & 2,083 & 69.3 \\
\hline Alimentary tract and metabolism (A) & 626 & 20.8 \\
\hline Nervous system $(\mathrm{N})$ & 137 & 4.6 \\
\hline Systemic hormonal preparations, excluding sex hormones and insulins & 74 & 2.5 \\
\hline General anti infectives for systemic use $(\mathrm{J})$ & 27 & 0.9 \\
\hline Respiratory system (R) & 23 & 0.8 \\
\hline Blood and blood forming organs (B) & 15 & 0.5 \\
\hline Dermatological (D) & 10 & 0.3 \\
\hline Cardiovascular system (C) & 9 & 0.3 \\
\hline \multicolumn{3}{|l|}{ ATC-2 codes } \\
\hline Anti-inflammatory and antirheumatic products (M01) & 1,156 & 38.5 \\
\hline Topical products for joint and muscular pain (M02) & 665 & 22.1 \\
\hline Drugs for acid related disorders (A02) & 515 & 17.1 \\
\hline Muscle relaxants (M03) & 259 & 8.6 \\
\hline Analgesics (N02) & 111 & 3.7 \\
\hline Corticosteroids for systemic use (H02) & 73 & 2.4 \\
\hline Vitamins (A11) & 60 & 2.0 \\
\hline Mineral supplements (A12) & 47 & 1.6 \\
\hline Antibacterials for systemic use (J01) & 27 & 0.9 \\
\hline Cough and cold preparations (R05) & 18 & 0.6 \\
\hline Others & 73 & 2.4 \\
\hline \multicolumn{3}{|l|}{ Drug names (ATC-5 Codes) } \\
\hline Pantoprazole (A02BC02) & 343 & 11.4 \\
\hline Diclofenac (M01AB05) & 212 & 7.1 \\
\hline Dexketoprofen + thiocolchicoside (M02AA27 + M03BX05) & 211 & 7.0 \\
\hline Escin + diethylamine salicylate (M02AC55) & 207 & 6.9 \\
\hline Piroxicam (M01AC01) & 191 & 6.4 \\
\hline Ibuprofen (M01AE01) & 160 & 5.3 \\
\hline Diclofenac + thiocolchicoside (M01AB05 + M03BX05) & 133 & 4.4 \\
\hline Phenyramidol (M03BX30) & 102 & 3.4 \\
\hline Acemetacin ( M01AB11) & 95 & 3.2 \\
\hline Naproxen (M01AE02) & 94 & 3.1 \\
\hline
\end{tabular}




\section{TABLE V}

Summary of the assessment of rational drug use with the WHO core prescribing indicators at the orthopedics and traumatology outpatient clinic

\begin{tabular}{|lcc|}
\hline The WHO core prescribing indicators & Analysis results & WHO optimal levels \\
\hline Average number of drugs per encounter & 2.9 & $1.6-1.8$ \\
Percentage of drugs prescribed by generic name & $0 \%$ & $100 \%$ \\
Percentage of encounters with an antibiotic prescribed & $2.6 \%$ & $\leq 30 \%$ \\
Percentage of encounters with an injection prescribed & $10.7 \%$ & $\leq 20 \%$ \\
Percentage of drugs prescribed from essential drugs list & $33.8 \%$ & $100 \%$ \\
\hline WHO: World Health Organization. & & \\
\hline
\end{tabular}

\begin{tabular}{|c|c|c|c|c|c|}
\hline \multirow[b]{3}{*}{ Age groups (year) } & \multicolumn{4}{|c|}{$\begin{array}{l}\text { TABLE VI } \\
\text { e prescribing indicators by age categories }\end{array}$} & \multirow{3}{*}{$\begin{array}{c}\text { Drugs prescribed from } \\
\text { essential drugs list } \\
\%\end{array}$} \\
\hline & \multicolumn{2}{|c|}{$\begin{array}{l}\text { Average number of drugs per } \\
\text { prescription }\end{array}$} & \multirow{2}{*}{$\begin{array}{c}\text { Prescriptions with } \\
\text { an antibiotic } \\
\% \\
\end{array}$} & \multirow{2}{*}{$\begin{array}{c}\text { Prescriptions with } \\
\text { an injection } \\
\% \\
\end{array}$} & \\
\hline & Median & Min-Max & & & \\
\hline $18-44$ & 3 & $1-7$ & 3 & 8.1 & 28.4 \\
\hline $45-64$ & 3 & $1-7$ & 2.7 & 11.5 & 35.9 \\
\hline$\geq 65$ & 3 & $1-6$ & 2.0 & 13.4 & 37.6 \\
\hline$p$ value & \multicolumn{2}{|c|}{$0.001^{*}$} & 0.776 & 0.123 & $0.038^{* *}$ \\
\hline
\end{tabular}

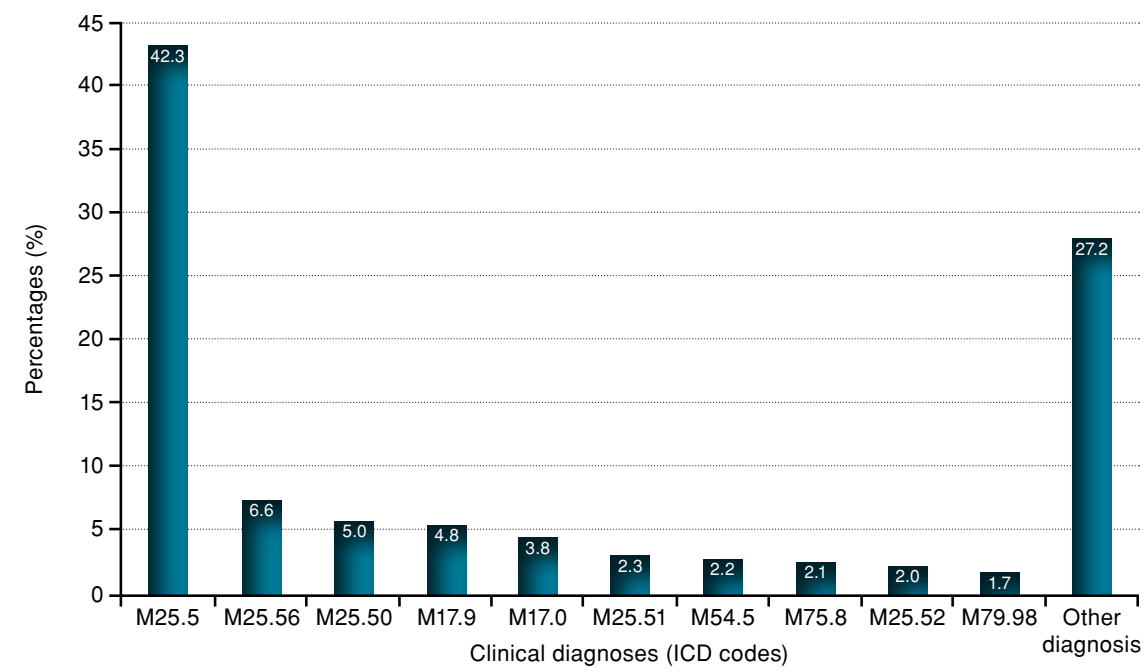

FIGURE 1. Percentages of the most common clinical diagnoses at orthopedics and traumatology outpatient clinic $(n=1,024)$.

M25.5: Pain in joint; M25.56: Pain in knee; M25.50: Pain in unspecified joint; M17.9: Osteoarthritis of knee, unspecified; M17.0: Bilateral primary osteoarthritis of knee; M25.51: Pain in shoulder; M54.5: Low back pain; M75.8: Other shoulder lesions; M25.52: Pain in elbow; M79.98: Soft tissue disorder, unspecified, other site. 


\section{DISCUSSION}

Considering that drug utilization studies are scarce in developing countries, ${ }^{[11]}$ this retrospective study is valuable in revealing the current situation regarding rational drug use. To the best of our knowledge, this is the first study to evaluate the rational drug use based on WHO prescribing indicators at an orthopedics and traumatology outpatient clinic in Turkey. ${ }^{[12]}$

In the present study, drug utilization patterns and rational drug use practices at the orthopedics and traumatology outpatient clinic of a tertiary care hospital were analyzed retrospectively based on WHO core prescribing indicators. The demographic features showed that most of the patients were female $(73.3 \%)$. This is in accordance with the results of a study conducted in orthopedic outpatient department which reported female preponderance. ${ }^{[13]}$ This finding could be explained by a higher prevalence of musculoskeletal disorders reported in women than men. ${ }^{[14]}$ Almost half of the patients were between 45 and 64 years of age $(47.7 \%)$ in our study. Similar to our results, two studies reported middle aged group as the most common age group at orthopedic departments. ${ }^{[13,15]}$

According to the clinical diagnosis, musculoskeletal pains constituted the majority of the diagnoses (Figure 1). Unlike our findings, two studies reported acute trauma and fractures as the most common diagnoses at the orthopedic departments. ${ }^{[15,16]}$

Non-steroidal anti-inflammatory drugs (NSAIDs) are frequently used drugs for the management of musculoskeletal conditions. ${ }^{[17]}$ Gastroprotective agents are commonly prescribed concomitantly with NSAIDs to reduce the adverse effects (gastrointestinal ulcers, bleeding), morbidity and mortality due to NSAIDs long-term use. ${ }^{[18]}$ In the present study, among drug classes, NSAIDs and drugs for acid-related disorders were the most frequently prescribed drug groups. Similar to our results, two studies from India and Nepal which assessed rational drug use at orthopedics and traumatology outpatient departments reported NSAIDs and anti-ulcer drugs as the most common drug classes. ${ }^{[19,20]}$

Although polypharmacy, which is an important example of irrational drug use, is usually known as the use of two or more drugs, there is no consensus on the exact definition. According to the current literature, it is commonly described as five or more drugs daily. ${ }^{[21]}$ In addition, using 10 or more drugs is defined as hyper-polypharmacy which is a problem among elderly. ${ }^{[21]}$ In our study, a great majority of the patients were prescribed two to four drugs (79.8\%), while a small percentage of patients were given five or more drugs $(7.5 \%)$. The average number of drugs per encounter in the present study was 2.9 , which is higher than the WHO standard values (1.6-1.8). ${ }^{[7]}$ Similar to our results, many studies from distinct countries reported higher values than WHO ideal ranges, differing from 2.36 to 5.79. ${ }^{[13,15,16,22-26]}$ Polypharmacy was significantly higher in patients aged $\geq 65$ years (average number of drugs per prescription: 3.1 ) than young adults aged between 18 and 44 years $(\mathrm{p}=0.001)$. This is an anticipated result due to the increased number of drugs used by increasing age related to existing comorbidities. ${ }^{[27]}$ Similarly, a study from Jordan which evaluated rational drug use at primary healthcare centers reported that polypharmacy was significantly higher among elderly. ${ }^{[28]}$

Antibiotic overuse is an important issue worldwide due to the risk for occurrence of antibiotic resistance. ${ }^{[29]}$ The percentage of encounters with an antibiotic prescribed in the present study was $2.6 \%$, which is within normal limits according to the WHO standard value $(\leq 30 \%)$. ${ }^{[7]}$ Similarly, several studies from distinct orthopedic departments reported antibiotic use within normal ranges differing from 1.09 to $8.43 .^{[16,19,25,26]}$ In contrast, quite high levels of antibiotic use $(60.4 \%)$ were reported in a study by Abhilash et al. ${ }^{[15]}$ which was conducted among orthopedic inpatients.

Keeping the injection prescribing to a minimum level both reduces the pharmacotherapy cost and minimize the risks of complications due to parenteral use. ${ }^{[24]}$ In contrast to other studies by Abhilash et al. ${ }^{[15]}(76.3 \%)$ and Srividya et al. ${ }^{[30]}$ $(46.84 \%)$, we found a low injection prescribing percentage (10.7\%), which is normal according to the WHO standard value $(\leq 20 \%) \cdot{ }^{[7]}$

The essential drug list of Turkey could be attained from the website of the Turkish Medicines and Medical Devices Agency under the head of 'SKRS3 e-prescription drug and other pharmaceutical products list' which is updated regularly. ${ }^{[31]}$ The essential drug list of Turkey has been prepared based on the WHO Model List of Essential Drugs and harmonized with relevant lists for essential drugs. The rate of drugs from essential drug list in our study was $33.8 \%$ which was quite low than the expected WHO value $(100 \%)^{[7]}$ and was found to be significantly lower in young adults compared to elderly $(p=0.038)$. Our result is consistent with those reported by Karki et al. ${ }^{[16]}$ who found that $34.3 \%$ of drugs were prescribed from essential drug list at the orthopedics department. In a recent 
study, which evaluated the rational drug use at the obesity outpatient clinic of a tertiary care hospital in Turkey, higher percentages of drugs prescribed from essential drug list were found (61.4\%). ${ }^{[32]}$ This discrepancy could be attributed to the type of outpatient clinic and the difference of prescribed drugs.

Prescribing with generic name not only lowers the pharmacotherapy costs, but also provides drug treatments to be more rational. ${ }^{[4]}$ Since the drugs are prescribed with their trade name in our country, we found the percentage of generic prescribing was $0 \%$, as expected. Similarly, a study conducted at an orthopedic outpatient department in India reported generic prescribing percentage as $0 \% .{ }^{[26]}$ Several studies evaluating the rational drug use at distinct orthopedic departments reported higher generic prescribing percentages than our study, although the values were far from the WHO expected percentage. ${ }^{[13,15,16,19,25,30]}$ For the rationalization of pharmacotherapy, it would be an outstanding step to launch prescribing drugs with generic names rather than trade ones in our country, as well.

Since irrational drug use is a global health problem which is both an important economic burden on society and also causes negative health consequences such as therapy failure, resistance to antibacterial drugs, adverse drugs reactions, considerable morbidity and mortality, ${ }^{[33]}$ it is crucial to emphasize the importance of rational drug use to physicians during both underand postgraduate education.

The present study has some limitations. Our study was conducted with a small sample size for a short period of time in a single tertiary care hospital and, thus, the results may not be representative for the Turkish population. Nevertheless, we believe that the present study would further shed light into the future multi-center studies with larger sample sizes in the long-term.

In conclusion, our study is the first to assess the drug use patterns and rational drug use practices based on the WHO prescribing indicators at an orthopedics and traumatology outpatient clinic in Turkey. Based on these findings, the percentage of encounters with an antibiotic and injection prescribed were found to be optimal according to WHO standards, while the average number of drugs per encounter was higher compared to the WHO ideal ranges. Unfortunately, the parameters, such as the percentage of prescribing with generic name and from essential drug list, were far more behind the optimal range. It is expected that our study would shed light into both the rationalization of pharmacotherapy and the implementation of relevant regulations on rational drug use by health authorities.

\section{Declaration of conflicting interests}

The authors declared no conflicts of interest with respect to the authorship and/or publication of this article.

\section{Funding}

The authors received no financial support for the research and/or authorship of this article.

\section{REFERENCES}

1. World Health Organization. Promoting rational use of medicine: core components. WHO Policy and Perspectives on Medicines, 2002. Available at: http://apps.who.int/ medicinedocs/pdf/h3011e/h3011e.pdf

2. Maxwell S. Rational prescribing: The principles of drug selection. Clin Med (Lond) 2009;9:481-5.

3. World Health Organization. The World Medicines Situation, Rational Use of medicines, 2011 WHO/EMP/MIE/2011.2.2. Available at: http://apps.who.int/medicinedocs/en/m/ abstract/Js1806en/

4. Demeke B, Molla F, Assen A, Melkam W, Abrha S, Masresha $\mathrm{B}$, et al. Evaluation of drugs utilization pattern using WHO prescribing indicators in Ayder Referral Hospital, Northern Ethiopia. International Journal of Pharma Sciences and Research 2015;6:343-7.

5. Nyabuti AO, Okalebo FA, Guantai EM. Examination of WHO/INRUD core drug use indicators at public primary healthcare centers in Kisii County, Kenya. Adv Pharmacol Pharm Sci 2020;2020:3173847.

6. Farooq MA, Khan I, Khan DH, Ahsan A, Hussain A, Mansoor I, et al. WHO indicators and its compliance by general practitioners of Lahore, Pakistan. Iranian Journal of Pharmaceutical Sciences 2019;15:67-74.

7. World Health Organization. Action programme on essential drugs and vaccines. How to investigate drug use in health facilities: Selected drug use indicators. World Health Organization; 1993. Available at: http://apps.who. int/medicinedocs/en/d/Js2289e/.

8. Sisay M, Mengistu G, Molla B, Amare F, Gabriel T. Evaluation of rational drug use based on World Health Organization core drug use indicators in selected public hospitals of eastern Ethiopia: A cross sectional study. BMC Health Serv Res.2017;17:161.

9. Hogerzeil HV, Bimo, Ross-Degnan D, Laing RO, Ofori-Adjei D, Santoso B, et al. Field tests for rational drug use in twelve developing countries. Lancet 1993;342:1408-10.

10. Yazıcıŏ̆lu Y, Erdoğan S. SPSS uygulamalı bilimsel araştırma yöntemleri. Ankara: Detay Yayıncılık. 2004. s. 50.

11. Maqbool R, Rehman SU. Drug utilization study in patients admitted in medical wards in a tertiary care rural hospital in North Kashmir. J Evolution Med Dent Sci 2020;9:1423-6.

12. Atik OŞ. What are the expectations of an editor from a scientific article? Jt Dis Relat Surg 2020;31:597-8.

13. Motgahre1 WM, Bajait CS, Turankar A, Pimpalkhute SA, Dholpure M. Prescription pattern and adverse drug reaction profile of drugs prescribed with focus on NSAIDs for orthopedic indications at a tertiary care hospital. Indian Journal of Pharmacy and Pharmacology 2016;3:178-81. 
14. Wijnhoven HA, de Vet HC, Picavet HS. Prevalence of musculoskeletal disorders is systematically higher in women than in men. Clin J Pain 2006;22:717-24.

15. Abhilash S, Rao RR, Sivaguha Yadunath P. Assessment of prescribing pattern among orthopedic in-patients using WHO prescribing indicators. Asian Journal of Pharmaceutical and Clinical Research 2018;11:505-9.

16. Karki N, Prasad P, Joshi RR, Shrestha BK. Drug utilization pattern by using WHO core prescribing indicators in orthopedics and obstetrics/gynecology departments of a tertiary care hospital. J Lumbini Med Coll 2019;7:18-23.

17. Atchison JW, Herndon CM, Rusie E. NSAIDs for musculoskeletal pain management:current perspectives and novel strategies to improve safety. J Manag Care Pharm 2013;19(9 Suppl A):S3-19.

18. Moore RA, Derry S, Simon LS, Emery P. Nonsteroidal antiinflammatory drugs, gastroprotection, and benefit-risk. Pain Pract 2014;14:378-95.

19. Shankar PR, Pai R, Dubey AK, Upadhyay DK. Prescribing patterns in the orthopaedics outpatient department in a teaching hospital in Pokhara, western Nepal. Kathmandu Univ Med J (KUMJ) 2007;5:16-21.

20. Kulkarni M, Patil A. Drug utilization study in the orthopedics outpatient department of a tertiary care hospital in maharashtra. Asian J Pharm Clin Res 2018;11:224-6.

21. Davies LE, Spiers G, Kingston A, Todd A, Adamson J, Hanratty B. Adverse outcomes of polypharmacy in older people: Systematic review of reviews. J Am Med Dir Assoc 2020;21:181-7.

22. Mamo DB, Alemu BK. Rational drug-use evaluation based on World Health Organization core drug-use indicators in a tertiary referral hospital, northeast Ethiopia: A crosssectional study. Drug Healthc Patient Saf 2020;12:15-21.

23. Mishore KM, Girma Y, Tola A, Mekuria AN, Ayele Y. Evaluation of medication use pattern among patients presenting to the emergency department of Hiwot Fana Specialized University Hospital, using WHO prescribing indicators. Front Pharmacol 2020;11:509.
24. Al-Azayzih A, Al-Azzam SI, Alzoubi KH, Shawaqfeh M, Masadeh MM. Evaluation of drug-prescribing patterns based on the WHO prescribing indicators at outpatient clinics of five hospitals in Jordan: A cross-sectional study. Int J Clin Pharmacol Ther 2017;55:425-32.

25. Solanki N, Patel Y. Drug utilization pattern and drug interaction study of antibiotics prescribed to orthopaedic patients in private hospital. Arch Pharma Pract 2019;10:114-7.

26. Ingle P, Patil PH, Lathi V. Study of rational prescribing and dispensing of prescriptions with nonsteroidal antiinflammatory drugs in orthopedic outpatient department. Asian Journal of Pharmaceutical and Clinical Research 2015;8:278-81.

27. Golchin N, Frank SH, Vince A, Isham L, Meropol SB. Polypharmacy in the elderly. J Res Pharm Pract 2015;4:85-8.

28. Alkhatib AR, Batieha AM, Abdo NM, Obeidat HM, Okour AHM. Assessment of drug prescribing in Jordan using World Health Organization indicators. Int J Hosp Pharm 2019;4:27.

29. Llor C, Bjerrum L. Antimicrobial resistance: Risk associated with antibiotic overuse and initiatives to reduce the problem. Ther Adv Drug Saf 2014;5:229-41.

30. Srividya BP, Shashikumar NS, Amardeep G. Retrospective audit of prescription of drugs among inpatients of orthopedic wards at Medical College Teaching Hospital, Mandya. National Journal of Physiology, Pharmacy and Pharmacology 2016;6:282-5.

31. Available at: https://www.titck.gov.tr/dinamikmodul/43

32. Özdamar EN, Mutlu HH. Evaluation of the rational drug use by using the World Health Organization core prescribing indicators at the obesity outpatient clinic of a tertiary care hospital. Ege Journal of Medicine 2021;60:13-9.

33. Akıcı A, Mollahaliloğlu S, Dönertaş B, Özgülcü Ş, Alkan A, Filiz Başaran N. Patients' attitudes and knowledge about drug use: A survey in Turkish family healthcare centres and state hospitals. Turk J Med Sci 2017;47:147281. 